\title{
Analysis of Herding Behavior in Moroccan Stock Market
}

\author{
Mustapha El hami, Ahmed Hefnaoui \\ Research laboratory in economic and logistics performance, Morocco \\ Elhami.mustapha85@email.com, hefnaoui_ahmed@yahoo.com
}

\begin{abstract}
Frontier markets, particularly the Moroccan financial market, are characterized by a narrowness of market, inability to absorb erratic price fluctuations and the low liquidity of securities that encourage investors to herd and imitate those who have all the information about the market. A quantitative research approach was used to analyze the existence of herding $n$ Moroccan stock market. The daily data used in this study concerns the period from 04/01/2010 to 29/12/2017 and contains the daily returns of the MASI and a total of 43 traded stocks. Statistical and econometric methods such as multidimensional scaling and Cross-sectional absolute deviation were used. Subsequently, after the regression models were examined, findings indicated that the first stocks with the highest similarity to the index return are BMCE, BCP, IAM, ATW and CMSR, and the first stocks with the highest dissimilarity are PAP, IBC and SNP, This will have to allow investors to choose profitable alternatives and avoid those that present a possible risk. The results did also show the existence of herding in the Moroccan stock market both upward and downward. This finding was supported by the clear existence of a non-linearity between market performance and CSAD measurement, which confirms the prediction of a nonlinear inversion relationship between CSAD and $R_{m}$. This could be due to the low level of transparency that prevails in frontier stock exchanges and reduces the quality of their information environment, which leads investors not to react rationally and to draw information from the transactions of their peers.
\end{abstract}

Keywords: Frontier markets, Herd behavior, Behavioral finance, Information, Moroccan index.

\section{Introduction}

In a few years, the efficient market hypothesis (EMH) has become the keystone of the entire financial theory. This hypothesis manifests in two points. The first point states that the market price is the price that reflects the intrinsic value of the assets, in other words, the "fundamentals". The second point indicates that prices include all available market information and that there is no arbitrage opportunity. The Darwinian idea states that in financial markets, only rational investors should remain (Broihanne \& Capelle-Blancard, 2018). However, a large number of researchers have rejected this hypothesis in the markets. Grossman \& Stiglitz (1980) have vehemently criticized this assumption of market efficiency since the early 1980s, stressing that, if markets were efficient, no economic agent would have an interest in acquiring (bearing the costs of acquiring) information. The two economists George A Akerlof (Nobel Prize winner) and Robert J. Shiller are well aware that the idea that economic crises, like the financial and real estate crisis, are mainly caused by a change in our perception of the world, goes against traditional economic thinking (Évariste LEFEUVRE, 2011). Thus, an understanding of the investor's behavior seems necessary to explain some of the different factors behind these anomalies. Given the importance of this behavior and its implications for financial markets, the literature has developed rapidly in recent years, partly because of the prolonged crisis in US financial markets, which subsequently spread to global markets.

In this context, behavioral finance argues that investors' herd behavior may explain some of the anomalies found in financial markets by assuming that investors tend to abandon their own beliefs and imitate others even when their private information suggests that they should make a different decision (Bikhchandani et al., 1992); (Devenow \& Welch, 1996), leading to a deviation of prices from their fundamental values and excessive market volatility. In this study, our interest is first to focus on a small illiquid capital market, which could influence herd behavior. Then, we use a multidimensional scaling approach to transform the data into similarity measures that can be represented by Euclidean distances in the space of unknown dimensions to display the proximities between the stocks and the stock index. Before considering a different approach to herd measurement based on the Cross-Sectional Absolute Deviation. This study covers a sufficiently long period to dilute the biases resulting from point fluctuations in the market. There are many reasons to study the effect of herd behavior on frontier markets, particularly the Moroccan financial market. First, the narrowness of markets and the low liquidity of securities in the frontier markets encourage investors to imitate those who 
have all the information about the market. Second, investors must understand that this type of market has high growth potential, and low and attractive valuations compared to emerging markets.

In doing so, they will benefit by ensuring a better allocation of assets, combined with risk management and strategic decision-making. The remainder of this document is organized as follows. Section 2 briefly summarizes previous studies on herding in general. Section 3 presents the methodology used in the herd behavior test. Section 4 presents an analysis of the data. Finally, section 5 proposes to give our conclusions.

\section{Literature Review}

A body of work carried out over time contributes to enriching the literature on herd behavior. Regarding this, we give a brief overview of mimicry in the financial markets. According to Hott (2009) if one player's decisions are positively influenced by the decisions of other players, this is called herd behavior. Christie \& Huang (1995) defines herding as a tendency of people to follow the performance of the global market, imitate the actions of others and ignore their own point of view. It could also be defined as a correlation in investor behavior. According to Avery \& Zemsky (1996), mimicry is defined as that of an agent negotiating against its initial assessment and instead of following the trend of previous exchanges. There are two types of herd behavior, "spurious" herding and intentional herding. When investors react with the same well-known public information and make the same investment decisions, it can be considered spurious herding (Park \& Kim, 2017). While, if investors intend to follow the behavior of others, this can be considered intentional herd behavior and the latter will be the subject of our study. In addition, there are several reasons behind intentional herd behavior.

First, according to Bikhchandani et al. (1992) there is the information cascade, which means that a slight preponderance of public information is sufficient to get people to follow the market leader and neglect their own knowledge. A second reason is the lack of information or the inferior quality of information, which can lead to mimicry based on compensation and reputation (Ren \& Wu, 2018). According to Li, Wang, and Rhee (2015), there are differences between institutional and retail investors in herd behavior. Li et al. (2015), according to a measure based on trading volume, found that well-informed institutional investors trade selectively while individual investors are less informed and distribute their investment evenly across assets, as well as individual investors rely more on public information and are influenced by market sentiment and attention-grabbing events. Institutional investors react asymmetrically to market movements up and down, while individual investors do not. Bailey and Ng (2010), using thousands of brokerage accounts of US retail investors, show that behavioral factors influence individual investors' decisions to hold individual stocks rather than mutual funds, including passive index funds.

Nevertheless, Deng et al. (2018) note that the herding of mutual funds deteriorates the quality of the company's information communication. Companies with a high mutual fund herding effect have less private information, less profit transparency, a higher probability of accounting errors and less accounting conservatism. The authors also find that there is a strong predictive relationship between mutual fund herd behavior and stock market crashes. In this regard, there is a wide range of studies analyzing the presence of herding in different markets and its potential impact on asset prices, which do not always come to the same conclusions. Yousaf, Ali and Shah (2018), using the Christie and Huang regression model (1995) and the Chang et al. (2000) model, examine herd behavior on the Pakistani stock exchange under different market conditions, focusing on the Ramadan effect and periods of crisis. They argue that there is no herd effect on the Karachi stock exchange. In addition, they argue that mimicry does not exist during the bull and bear market as well as during high or low volatility in the market. It is detected only during the low trading volume in Pakistan and is not influenced by the month of Ramadan.

Ahsan and Sarkar (2013), using Cross-Sectional Standard Deviation (CSSD) and Cross-Sectional Absolute Deviation (CSAD) techniques, did not detect the existence of a herd effect on the Dhaka stock exchange in Bangladesh for the period January 2005 to December 2011, including the December 2010 crash. However, Ren and $\mathrm{Wu}$ (2018), using an innovative and forward-looking method to examine investors' herd behavior and identify false herding driven by fundamentals in the Chinese stock market, indicate that there is real and significant behavior among blue chips. Vo and Phan (2017) examine the presence of herd behavior on the 
Vietnamese stock market from a sample of 299 companies listed on the Ho Chi Minh City Stock Exchange covering the period 2005- 2015. The study uses the herding measures proposed by Christie and Huang (1995) and Chang, Cheng and Khorona (2000) on a daily, weekly and monthly frequency, therefore, indicates the existence of herding over the entire period studied. Gong and Dai (2017) indicate that rising interest rates and the depreciation of the Chinese currency (CNY) will lead to the formation of mimicry and this phenomenon occurs mainly in bear markets.

The authors Theriou, Mlekanis and Maditinos (2011) used the methodology based on the Lakonishok, Shleifer and Vishny (1992) model to investigate the behavior of managers of mutual funds investing on the Athens stock exchange during the period 2001 - 2006. The study indicated the existence of herd behavior when mutual fund managers trade large-cap stocks or stocks in the most "famous" indexes. Data on herd behavior in frontier markets have generated considerable research interest. Economou (2016) examines herding in two African border markets - Nigeria and Morocco - that have not been analyzed previously, using daily data for the period 2004-2014. The empirical results obtained using the reference model of Chang et al. (2000), do not indicate the presence of herding. However, when he tested asymmetries in mimicry estimates, he identified herd behaviors during days of bear market volatility for Nigeria.

Moreover, there is evidence of mimicry during the global financial crisis only in Morocco. Structural failure tests reveal significant evidence of herding in Morocco for the sub-period from December 2005 to December 2014, with herding being more pronounced on days of high market and volume volatility. According to Guney, Kallinterakis and Komba (2017), Elhami and Hefnaoui (2018) herding is present on African frontier markets, this is attributed to the low levels of transparency that prevail in border exchanges and that reduce the quality of their information environment, as well as it leads investors to consider herding as a feasible option, allowing them to deduce information from their peers' transactions. Similarly, the increased informational uncertainty surrounding small stocks is pushing investors to trade them more under the influence of herding. Balcilar, Demirer and Hammoudeh (2012), when studying the Gulf countries find evidence of herd behavior under the crash regime for all markets except Qatar, where herd effects are subject to low and high volatility regimes.

\section{Methodology}

This study first focuses on multidimensional scaling analysis developed by F.Cox and A.A.Cox (2000) as a technique developed to measure and predict human judgment. Multidimensional scaling (MDS) is a mathematical technique that allows us to map the distances between points in a high dimensional space in lower dimensional space. This is more useful when we can draw a map in a two-dimensional space because it will help us to visually confirm the different groups of classes (clusters). The result of an MDS analysis is the transformation of data into similarity measures that can be represented by Euclidean distances in the space of unknown dimensions (Borg and Groenen, 2005). In the MDS method, a small distance between two points corresponds to a high correlation between two actions and a large distance corresponds to a low or even negative correlation (Nirenberg and Latham, 2003). MDS can be considered as an exploratory technique without any assumption of data distribution. The distances between points on MDS maps are generally not difficult to interpret and can, therefore, be used to formulate more specific models or assumptions.

In addition, the distance between two points must be interpreted as the conditional distance at all other distances. Secondly, on the analysis of the relationship between the variables Cross-Sectional Absolute deviation CSAD of equity return rates from the market return rate in period $t$, the equity return rate i in period $\mathrm{t} R_{i, t}$ and the market portfolio return in period $\mathrm{t} R_{m, t}$. The daily data used in this study, which contains the daily returns of the MASI (Moroccan all shares index) and a total of 43 traded shares shown in Table 1, cover the period from 04/01/2010 to 29/12/2017. The data set was obtained from the global financial portal and Internet brand ${ }^{1}$. In our study, daily return data calculated on the basis of the closing prices of each share and

\footnotetext{
${ }^{1}$ https://fr.investing.com/.
} 
the index were analyzed using the regression method. Some shares were not included in the analysis because data on them were not available for the period studied. We applied the logarithmic yield determined as follows $R_{t}=\ln \left(\frac{P_{t}}{P_{t-1}}\right)$ Where $P_{t}, P_{t-1}$ is the stock price.

This study used a CSAD model of stock returns developed by Chang, Cheng and Khorana (2000), which is a nonlinear and growing function of market returns. In formula (1), the CSAD $t$ variable represents the cross-sectional absolute deviation of stock return rates from the market return rate in period $\mathrm{t}$, the $R_{i, t}$ variable represents the stock return rate i in period $\mathrm{t}$, the $R_{m, t}$ variable represents the market portfolio return in period $\mathrm{t}$ and the $\mathrm{N}$ variable represents the number of stocks.

$C S A D_{t}=\frac{\sum_{i=1}^{N}\left|R_{i, t}-R_{m, t}\right|}{N}$

To take into account the possibility that the degree of herding may be asymmetric at the top compared to the bottom of the range, we use the following empirical specification. Two models will be used to measure herd behavior in bullish (upwards) and bearish (downwards) markets, respectively, and will be presented as follows.

$$
\begin{aligned}
& C S A D_{t}^{U P}=\alpha+\gamma_{1}^{U P}\left|R_{m, t}^{U P}\right|+\gamma_{2}^{U P}\left(R_{m, t}^{U P}\right)^{2}+\varepsilon_{t} \\
& \text { If } R_{m, t} \geq 0 \\
& C S A D_{t}^{\text {DOWN }}=\alpha+\gamma_{1}^{\text {DOWN }}\left|R_{m, t}^{D O W N}\right|+\gamma_{2}^{D O W N}\left(R_{m, t}^{D O W N}\right)^{2}+\varepsilon_{t} \\
& \text { If } R_{m, t} \leq 0
\end{aligned}
$$

If, during periods of relatively large price fluctuations, market participants gather around indicators such as the average consensus of all market components, this would result in a non-linear relationship between the $\mathrm{CSAD}_{t}$ and the average market return. Non-linearity would be captured by a negative and statistically significant $\gamma_{2}$ coefficient.

\section{Table 1: The Stocks Analyzed}

\begin{tabular}{llll}
\hline Action & Code & Action & Code \\
\hline Afriquia gaz & AGAZ & Label vie & LBV \\
Auminiummaroc & ALU & Lesieur & LESU \\
Atlanta & ATL & LafargeHolcim Ltd & LHM \\
Auto hall & AUTO & Lydec & LYD \\
Attijariwafabank & ATW & M2M group & M2M \\
Bcp & BCP & MicroData SA & MIC \\
Bmce & BMCE & Nexans SA & NEX \\
Bmci & BMCI & Maghreb oxygene & OXYG \\
Creditmaroc & CDM & Med Paper & PAP \\
Cih & CIH & Promopharms.a & PRO \\
Minieretouissit & CMT & Risma & RIS \\
Colorado & COL & Saham Assurance & SAH \\
Cartier saada & CRS & Brasseries maroc & SBM \\
Cosumar & CMSR & Ciments du maroc & SCM \\
Ctm-ln & CTM & Salafin & SLF \\
Delta holding & DHO & Smi & SMI \\
Dellatre lev & DLM & Stokvis nord & SNA \\
Disway SA & DWY & Snep & SNP \\
CreditEqdm & EQDM & Sonasid & SOND \\
\hline
\end{tabular}




\begin{tabular}{llll}
\multicolumn{4}{c}{$\begin{array}{c}\text { Journal of Economics and Behavioral Studies (ISSN: 2220-6140) } \\
\text { Vol. 11, No. 1, pp. 181-190, February 2019 }\end{array}$} \\
\hline \hline & & & \\
\hline Maroc telecom & IAM & Timar & TIM \\
IB Maroc Com SA & IBC & Wafa assurance & WASS \\
Jet Contractors & JET & Moroccan All Shares & MASI \\
\hline
\end{tabular}

\section{Empirical Results}

\section{Descriptive Statistics}

Table 2: Descriptive Statistics Results

\begin{tabular}{|c|c|c|c|c|}
\hline & Mean & Minimum & Maximum & Std. DEV \\
\hline MASI & 0,000083 & $-0,030338$ & 0,032955 & 0,006196 \\
\hline AGAZ & 0,000906 & $-0,097638$ & 0,060586 & 0,018205 \\
\hline ALU & 0,000139 & $-0,124669$ & 0,084866 & 0,020696 \\
\hline ATL & $-0,000099$ & $-0,073773$ & 0,095145 & 0,018579 \\
\hline ATW & 0,000304 & $-0,061824$ & 0,058269 & 0,011902 \\
\hline AUTO & 0,000150 & $-0,090972$ & 0,088795 & 0,018612 \\
\hline ВСР & 0,000422 & $-0,097061$ & 0,066273 & 0,011346 \\
\hline BMCE & $-0,000116$ & $-0,061875$ & 0,081119 & 0,014368 \\
\hline BMCI & $-0,000018$ & $-0,087706$ & 0,094716 & 0,020550 \\
\hline CDM & $-0,000240$ & $-0,184677$ & 0,175288 & 0,021527 \\
\hline $\mathrm{CIH}$ & $-0,000062$ & $-0,078411$ & 0,116460 & 0,019353 \\
\hline CMT & 0,000290 & $-0,331157$ & 0,128891 & 0,021944 \\
\hline COL & 0,000160 & $-0,229432$ & 0,182420 & 0,022721 \\
\hline CRS & 0,000340 & $-0,102573$ & 0,095310 & 0,021075 \\
\hline CMSR & 0,000773 & $-0,104360$ & 0,095310 & 0,016935 \\
\hline CTM & 0,000947 & $-0,165060$ & 0,227390 & 0,019713 \\
\hline DHO & 0,000017 & $-0,109972$ & 0,095016 & 0,020345 \\
\hline DLM & $-0,000586$ & $-0,246988$ & 0,116085 & 0,026367 \\
\hline DWY & 0,000084 & $-0,123629$ & 0,135197 & 0,021569 \\
\hline EQDM & $-0,000387$ & $-0,114959$ & 0,112478 & 0,018435 \\
\hline IAM & $-0,000008$ & $-0,105292$ & 0,058269 & 0,010656 \\
\hline IBC & $-0,000943$ & $-0,246652$ & 0,174713 & 0,029316 \\
\hline JET & $-0,000299$ & $-0,146603$ & 0,174576 & 0,023997 \\
\hline LBV & 0,000391 & $-0,093496$ & 0,094444 & 0,019070 \\
\hline LESU & 0,000254 & $-0,079354$ & 0,094665 & 0,016437 \\
\hline LHM & 0,000296 & $-0,104988$ & 0,095065 & 0,020166 \\
\hline LYD & 0,000586 & $-0,105176$ & 0,090972 & 0,020487 \\
\hline M2M & $-0,000015$ & $-0,105361$ & 0,095283 & 0,025949 \\
\hline MIC & 0,000540 & $-0,150648$ & 0,115155 & 0,023576 \\
\hline NEX & $-0,000754$ & $-0,308122$ & 0,177169 & 0,024264 \\
\hline OXYG & $-0,000268$ & $-0,210162$ & 0,285842 & 0,023655 \\
\hline PAP & $-0,000852$ & $-0,430490$ & 0,189882 & 0,032591 \\
\hline PRO & 0,000939 & $-0,174617$ & 0,189791 & 0,022234 \\
\hline RIS & $-0,000364$ & $-0,105171$ & 0,095310 & 0,025590 \\
\hline SAH & $-0,000015$ & $-0,103990$ & 0,094700 & 0,018733 \\
\hline SBM & $-0,000521$ & $-0,165880$ & 0,115513 & 0,017638 \\
\hline SCM & 0,000423 & $-0,104573$ & 0,094771 & 0,020145 \\
\hline SLF & 0,000392 & $-0,135126$ & 0,060535 & 0,015988 \\
\hline SMI & 0,000644 & $-0,143183$ & 0,058269 & 0,021844 \\
\hline SNA & $-0,000638$ & $-0,093578$ & 0,095182 & 0,021470 \\
\hline SNP & 0,000133 & $-0,210495$ & 0,189937 & 0,029938 \\
\hline SOND & $-0,000599$ & $-0,106336$ & 0,095310 & 0,025538 \\
\hline TIM & $-0,000422$ & $-0,123623$ & 0,095289 & 0,019773 \\
\hline WASS & 0,000725 & $-0,080864$ & 0,094288 & 0,019602 \\
\hline
\end{tabular}


The descriptive statistics table shows, for the period from 04.01 .2010 to 29.12 .2017 , the average of the daily returns of the shares and the MASI main index, their minimum and maximum values and the corresponding standard deviations. The average return of the MASI index is $0.0083 \%$. During the period studied, the highest daily return of the MASI index was 3.3\% on 23.12.2016 and its lowest daily return was $-3 \%$ on 21.03.2011. Several factors have come together to drive the market towards this considerable decline, including the effect of the "Arab Spring", the departure of non-strategic foreign investors, the disaffection of local investors, investor arbitrage in favor of other safe investment instruments (bond UCITS, term deposits etc.). Among all stocks, the top three securities generating the highest average daily returns were CTM $(0.0947 \%)$, PRO $(0.0939 \%)$ and AGAZ $(0.0906 \%)$ respectively, while the lowest average daily returns were recorded for IBC ($0.00943 \%)$, PAP $(-0.0852 \%)$, and NEX $(-0.0754 \%)$.

Multidimensional Scaling Analysis: The multidimensional scaling technique has been implemented in the STATISTICA software. In our study, we used the MDS to allow us to analyze the correlation matrix between each of the two stocks forming a pair $(\mathrm{i}, \mathrm{j})$. Stress values are used to indicate model quality and adjustment data. According to Kruskal's model recommendation, stress of $20 \%$ or more is considered a bad model, $10 \%$ is considered reasonable, $5 \%$ is a good model and $2.5 \%$ is excellent (Hair et al., 2009). As the value of stress approaches zero, a better quality of adjustment would be achieved. The results of the MDS analysis in Table 3 reveal the following: For k-dimension $=2$, the iteration was repeated until the value was 0.2558005 in the 28th iteration. The solution obtained was considered appropriate since the stress value is close to 0 , which means that the relationship between the experience data and the distances in the configuration is a monotonous relationship.

\section{Table 3: Stress Value}

\begin{tabular}{ll}
\hline 44 Vars. from file & \\
\hline Number of dimensions: 2 & \\
Start config.: (Guttman-Lingoes) & \\
Last iteration computed: $59 ;$ & Best iteration: 28 \\
D-star: Raw stress $=154,5415 ;$ & Alienation $=0,2797001$ \\
D-hat: Raw stress $=126,6800 ;$ & Stress $=0,2558005$ \\
\hline
\end{tabular}

The empirical study reveals the first stocks closest and most distant to the index (MASI) return in accordance with variables' values (Euclidean distances) in figure 1. The first stocks with the highest similarity (proximity) to the index return are BMCE, BCP, IAM, ATW and CMSR, while the first stocks with the highest dissimilarity (distance) are PAP, IBC and SNP. Based on the positioning of the stocks in the MDS map, it appears that the returns or losses generated by the stocks that are similar to the performance of the Index will be approximately the same as those of the Index, while dissimilar stocks may produce returns or losses that are different from the Index. In addition, it could be argued that similar stocks could be included as alternatives to each of them in the portfolio construction process, while those that are dissimilar cannot be used as alternatives to each other. A review of the Shepard diagram in Figure 2 suggests that the distances between stocks and the index are linearly related, it identifies a strong correlation between observed distances and disparities (i.e. between initial distances and calculated distances), and thus a good quality of fit.

Regression Analysis: Tables present the regression results for Model 1 (upmarket) and Model 2 (down market), between the CSAD cross-sectional absolute deviation and the index returns. Model 1 shows that the parameter $\gamma_{1}$ (up) equal to 0.791 is statistically significant and positive at the $5 \%$ level, this result is explained by the fact that an increase in index returns significantly increases cross-sectional variability. The objective of the study was to determine the existence of investors' herd behavior on the Moroccan financial market. The analysis first focused on the multidimensional scaling MDS stipulating the construction of a perceptual space to reveal similarities and dissimilarities between stocks returns and the main stock market index. 
Figure 1: MDS Map

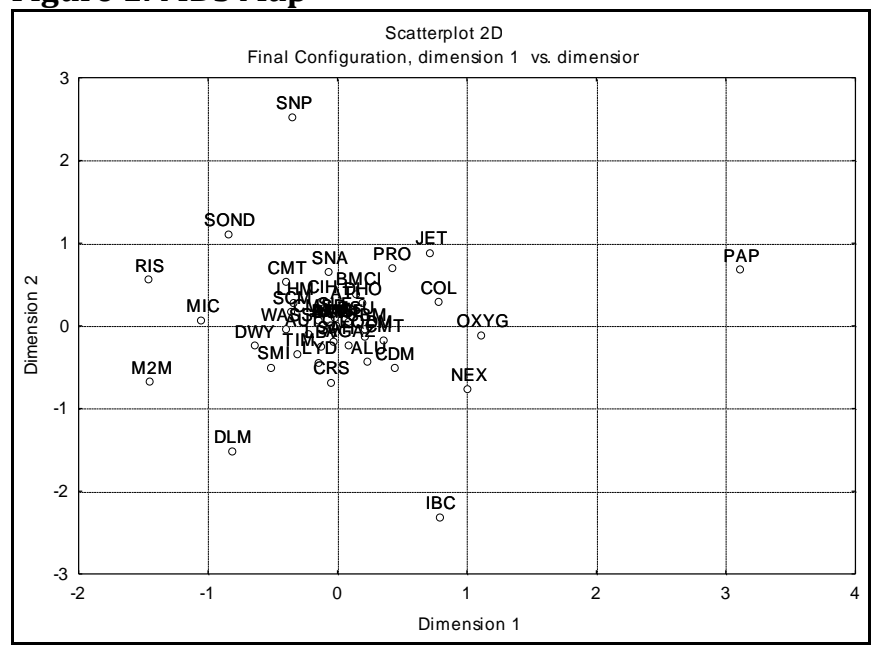

In addition, model 1 show that the second parameter $\gamma_{2}$ (up) equal to -6.29664 is statistically significant and negative at the $5 \%$ level this result could confirm the presence of herd behavior in the rising market. The result obtained indicates a non-linear and negative relationship between the cross sectional absolute deviation and the index returns. Since the non-linear term is significantly negative, the $C S A D_{t}$ increased at a decreasing rate or decreased as the average price movement increases. Therefore, in the case of extreme values in index returns, the cross sectional absolute deviation decreases and the herd behavior is observed during these stressful days. These results confirm the presence of a non-linear relationship and therefore support the argument that herd behavior is a valid phenomenon in the Moroccan financial market.

\section{Figure 2: Shepard Diagram (Distribution of Stocks and Index)}

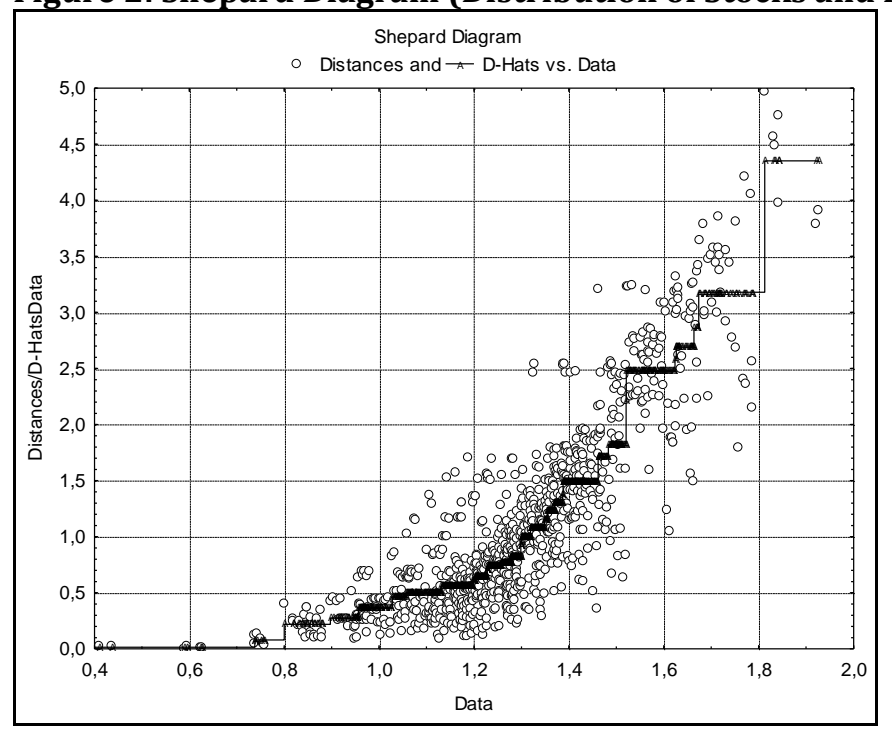

Model 2 (down market) shows results indicating the presence of herd behavior in the market when it is declining. The results obtained by the regression analyses indicate that the parameter $\gamma_{2}$ (down) is negative and statistically significant. It could, therefore, be argued that herd behavior towards the market is valid in the MASI in both bull and bear markets, but not linear. The results obtained are in line with those of other literature studies, in particular the Economou study (2016), which found a clear existence of herd behavior in Nigeria and Morocco in 2005. Given the results we have observed, herding behavior is present on the Moroccan stock market and we attribute it to the low level of transparency that prevails in frontier stock exchanges and reduces the quality of their information environment, which leads investors not to react rationally and to draw information from the transactions of their peers. 
Table 4: Market Up Model

\begin{tabular}{|c|c|c|c|c|}
\hline & \multicolumn{4}{|l|}{ Model 1} \\
\hline & \multicolumn{4}{|c|}{$C S A D_{t}^{U P}=\alpha+\gamma_{1}^{U P}\left|R_{m, t}^{U P}\right|+\gamma_{2}^{U P}\left(R_{m, t}^{U P}\right)^{2}+\varepsilon_{t}$} \\
\hline & Coefficient & Std. Error & T-statistic & Prob \\
\hline$\alpha$ & 0,00978 & 0,000184 & 53,13630 & 0,000000 \\
\hline$\gamma_{1}$ & 0,79085 & 0,070013 & 11,29572 & 0,000000 \\
\hline$\gamma_{2}$ & $-6,29664$ & 5,002516 & $-1,25869$ & 0,208411 \\
\hline F-statistic & 281.6887 & & & \\
\hline R-adjust & 0.339739 & & & \\
\hline
\end{tabular}

Table 5: Market Down Model

\begin{tabular}{|c|c|c|c|c|}
\hline & Model 2 & & & \\
\hline & $C S A D_{t}^{\text {DOWN }}=0$ & ${ }_{t}^{\text {OWN }} \mid+\gamma_{2}^{\text {DOWN }}(R$ & & \\
\hline & Coefficient & Std. Error & T-statistic & Prob \\
\hline$\alpha$ & 0,00974 & 0,000202 & 48,22467 & 0,000000 \\
\hline$\gamma_{1}$ & 0,82055 & 0,072683 & 11,28953 & 0,000000 \\
\hline$\gamma_{2}$ & $-6,77106$ & 4,674062 & $-1,44865$ & 0,147786 \\
\hline F-statistic & 280.1419 & & & \\
\hline R-adjust & 0.383099 & & & \\
\hline
\end{tabular}

To further illustrate the extent of non-linearity in the CSAD-Market relationship, in Figure 3 below, we plot the CSAD measure for each day and the corresponding equally weighted market performance for Model 1 and Model 2. The layout of the Moroccan financial market gives an insight into the presence of herd behavior in the market, where the non-linearity between market performance and the CSAD measure is evident. It confirms the prediction of a non-linear inversion relationship between CSAD and $R_{m}$, in alignment with Chang et al. (2000).

Figure 3a: Relationship between Cross-Sectional Absolute Deviation (csad) and Market Return $\mathbf{R}_{\mathrm{m}}, \mathbf{t}$ in Model 1

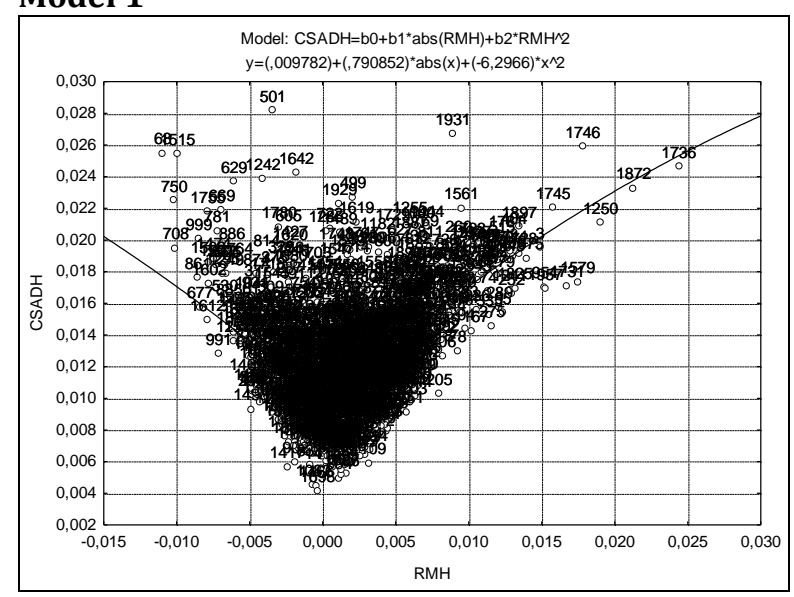


Figure 3-b: Relationship between Cross-Sectional Absolute Deviation (CSAD) and Market Return $\mathbf{R}_{\mathrm{m}}, \mathbf{t}$ in Model 2

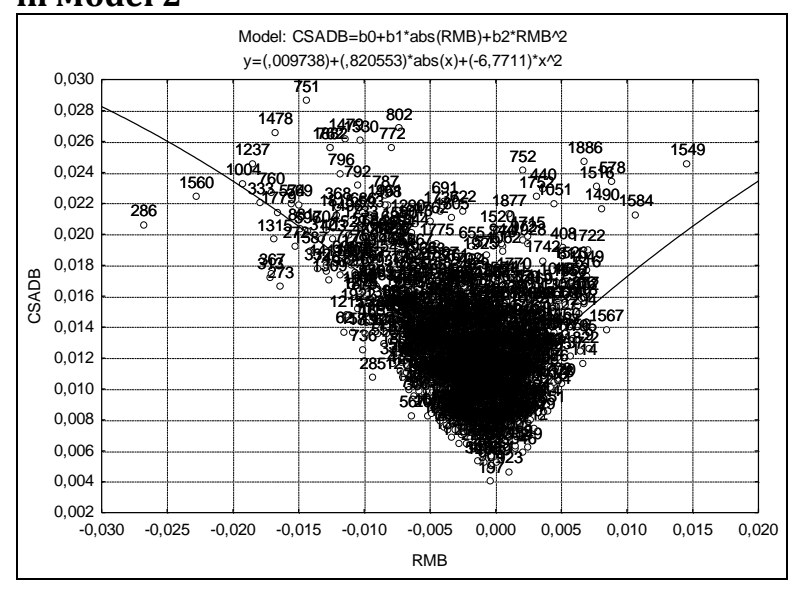

\section{Conclusion and Recommendations}

The objective of the study was to determine the existence of herding behavior in the Moroccan financial market. The analysis first focused on the multidimensional scaling MDS stipulating the construction of a perceptual space to display similarities and dissimilarities between stocks returns and the main stock market index. This study brought to light that the first stocks with the highest similarity to the index return are BMCE, BCP, IAM, ATW and CMSR, whereas the first stocks with the highest dissimilarity are PAP, IBC and SNP. This will have to allow investors to choose profitable alternatives and avoid those that present a possible risk. This preliminary analysis was supported by the analysis of investors' herd behavior using the CSAD methodology developed by Chang et al. (2000). The results obtained by the regression analysis showed the existence of herd behavior in Moroccan stock market both upward and downward. This finding was supported by the clear existence of a non-linearity between market performance and CSAD measurement, which confirms the prediction of a nonlinear inversion relationship between CSAD and $R_{m}$, in the spirit of Chang et al. (2000). The results obtained are in line with those of other literature studies, in particular the Economou's study (2016), which found a clear existence of herd behavior in Nigeria and Morocco in 2005.

Given the results we have observed, herding behavior is present on the Moroccan stock market and we assign it to the low level of transparency that prevails in frontier stock exchanges and reduces the quality of their information environment, which induces investors not to react rationally and to draw information from the transactions of their peers. In terms of suggestion, future studies should use a fuzzy logical approach to take into account herding and other behavioral biases to study investors' decision-making process and offer them the opportunity to make an optimal choice of trading strategies in the market. The high presence of herd behavior in African frontier markets suggests that regulatory measures to stem it (e.g. by increasing transparency and investor confidence and allaying investor concerns) are necessary to prevent the emergence of destabilizing outcomes. With the objective to improve the quality of the information environment, such measures will make these markets more attractive to foreign investors and increase their volume, which is essential to the sustainability of these markets and their development towards emerging markets.

\section{References}

Ahsan, A. F. M. M. \& Sarkar, A. H. (2013). Herding in Dhaka Stock Exchange. Journal of Applied Business and Economics, 14(2), 11-19.

Avery, C. \& Zemsky, P. (1996). Multidimensional Uncertainty and Herd Behavior in Financial Markets. American, The Review, Economic.

Bailey, W. \& Ng, D. (2010). Behavioral Biases of Mutual Fund Investors.

Balcilar, M., Demirer, R. \& Hammoudeh, S. (2012). investor Herds and Regime-Switching: Evidence from Gulf Arab Stock Markets Mehmet. Journal of International Financial Markets Institutions and Money.

Bikhchandani, S., Hirshleifer, D. \& Welch, I. (1992). A Theory of Fads, Fashion, Custom, and Cultural Change as 
Informational Cascades. Journal of Political Economy, 100(5), 992-1026.

Borg. \& Groenen, P. (2005). Modern Multidimensional Scaling: Theory and Applications. Springer New York.

Broihanne, M. H. \& Capelle-Blancard, G. (2018). Richard Thaler Ou Comment La Finance Est Devenue Comportementale.(Richard Thaler or How Finance Became Behavioural), 128.

Chang, E. C., Cheng, J. W. \& Khorana, A. (2000). An examination of herd behavior in equity markets: An international perspective. Journal of Banking \& Finance, 24, 1651-1679.

Christie, W. G. \& Huang, R. D. (1995). Following the Pied Piper: Do Individual Returns Herd around the Market? Financial Analysts Journal, 51(4), 31-37.

Deng, X., Hung, S. \& Qiao, Z. (2018). Mutual fund herding and stock price crashes. Journal of Banking and Finance, 94, 166-184.

Devenow, A. \& Welch, I. (1996). Rational herding in financial economics. European Economic Review, 40(3-5), 603-615.

Economou, F. (2016). Herd Behavior in Frontier Markets: Evidence from Nigeria and Morocco. Handbook of Frontier Markets: The African, European and Asian Evidence. Elsevier.

Elhami, M. \& Hefnaoui, A. (2018). l'efficience du marché dans les marchés émergents et frontières de la zone MENA. Finance \& Finance Internationale, 10.

Évariste LEFEUVRE. (2011). Marchés financiers, la logique du hasard - Rapprocher les marchés et l'économie pour ne plus subir l'imprévisible. (E. D’Organisation, Éd.) (7 juill).

F.Cox, T. \& Cox, M. A. A. (2000). Multidimensional Scaling, Second Edition (seconde).

Gong, P. \& Dai, J. (2017). Monetary policy, exchange rate fluctuation, and herding behavior in the stock market. Journal of Business Research, 76, 34-43.

Grossman, S. J. \& Stiglitz, J. E. (1980). American Economic Association On the Impossibility of Informationally Efficient Markets. The American Economic Review, 70(3), 393-408.

Guney, Y., Kallinterakis, V. \& Komba, G. (2017). Herding in frontier markets: Evidence from African stock exchanges. Journal of International Financial Markets, Institutions and Money, 47, 152-175.

Hair Junior, J. F., Black, W. C., Babin, B. J., Anderson, R. L. \& Tatham, R. L. (2009). Análise Multivariada de Dados. Tradução Adonai Schlup Sant'Anna.

Hott, C. (2009). Herding behavior in asset markets. Journal of Financial Stability, 5(1), 35-56.

Lakonishok, J., Shleifer, A. \& Vishny, R. W. (1992). The Impact of Institutional Stock Prices. Journal of Financial Economics, 32, 23-43.

Li, W., Wang, S. S. \& Rhee, G. (2015). Differences in Herding : Individual vs . Institutional Investors.

Nirenberg, S. \& Latham, P. E. (2003). Decoding neuronal spike trains: How important are correlations? Proceedings of the National Academy of Sciences, 100(12), 7348-7353.

Park, B. J. \& Kim, M. J. (2017). A Dynamic Measure of Intentional Herd Behavior in Financial Markets. MPRA Paper, (11543).

Ren, R. \& Wu, D. (2018). An Innovative Sentiment Analysis to Measure herd behavior. IEEE Transactions on Systems, Man, and Cybernetics: Systems, 1-11.

Theriou, N., Mlekanis, G. \& Maditinos, D. (2011). Herding by Mutual Fund Managers in the Athens Stock Exchange. European Research Studies Journal, XIV(4).

Vo, X. V. \& Phan, D. B. A. (2017). Further evidence on the herd behavior in Vietnam stock market. Journal of Behavioral and Experimental Finance, 13, 33-41.

Yousaf, I., Ali, S. \& Shah, S. Z. A. (2018). Herding behavior in Ramadan and financial crises: the case of the Pakistani stock market. Financial Innovation, 4(1), 16. 